\title{
GMR
}

\section{Case Report \\ Cytogenetic aspects of a canine breast carcinosarcoma - a case report}

\author{
C.S.D. Morais ${ }^{1}$, P.R.A.M. Affonso ${ }^{2}$, J.A. Bitencourt ${ }^{2}$ and A.A. Wenceslau ${ }^{1}$ \\ ${ }^{1}$ Programa de Pós-Graduação em Ciência Animal, \\ Departamento de Ciências Agrárias e Ambientais Ilhéus, BA, Brasil \\ ${ }^{2}$ Programa de Pós-Graduação em Genética, Biodiversidade e Conservação, \\ Departamento de Biologia, Jequié, BA, Brasil \\ Corresponding author: C.S.D. Morais \\ E-mail: cimovet@yahoo.com.br
}

Genet. Mol. Res. 16 (2): gmr16029433

Received October 13, 2016

Accepted April 12, 2017

Published May 25, 2017

DOI http://dx.doi.org/10.4238/gmr16029433

Copyright (C) 2017 The Authors. This is an open-access article distributed under the terms of the Creative Commons Attribution ShareAlike (CC BY-SA) 4.0 License.

\begin{abstract}
This study searched a rare and aggressive type of cancer in dogs and humans, the breast carcinosarcoma. Both clinical and pathological traits of mammary carcinosarcomas in dogs are similar to humans, such as infrequent occurrence, fast tumor growth, and unfavorable prognosis when compared to carcinomas. Other possible alterations include chromosomal abnormalities that can be useful for the identification of tumoral cells and diagnosis. The aim of this study was to compare the chromosomal features of peripheral lymphocytes and tumor cells in a mammary carcinosarcoma of a 14-year-old female Poodle. Chromosomes were analyzed from 210 metaphases by conventional Giemsa staining, C-banding, and base-specific fluorochrome staining with chromomycin A3 $\left(\mathrm{CMA}_{3}^{+}\right)$and DAPI. Of the 105 blood cells, $56.3 \%$ followed the standard karyotype of dogs $(2 n=78)$. In contrast, the carcinosarcoma cells showed high chromosomal numbers (104 to 153 ), divided into $80 \%$ hypertriploid (118 to 136 chromosomes), $10.5 \%$ hypotetraploid (137 to 153 chromosomes), $5.7 \%$ hypotriploid (104 to 116 chromosomes), and 3.8\% triploid cells (117 chromosomes). Among the aneuploid cells identified, we highlighted the trisomy of
\end{abstract}

Genetics and Molecular Research 16 (2): gmr16029433 
pair 1 and $\mathrm{X}$ chromosome once these elements were easily recognized in karyotype because of their size (pair 1) or differential morphology. Heterochromatin in normal cells was restricted to the pericentromeric region of all chromosomes while few C-bands were observed in tumor cells. This apparent loss of heterochromatin in neoplastic cells was supposed to favor centric fusion among formerly acrocentric chromosomes. Fluorochrome staining reinforced this hypothesis once GC-rich segments $\left(\mathrm{CMA}_{3}^{+}\right)$were identified on 10 chromosomes from normal cells $(2 n=78)$ whereas carcinosarcoma metaphases had up to 11 chromosomes bearing $\mathrm{CMA}_{3}$ signals in spite of their remarkable high chromosomal numbers. We concluded that, like in humans, the carcinosarcoma in dogs caused genome instability that eventually led to structural and numerical chromosomal aberrations. Besides, this study reinforced the importance of cytogenetic studies in dogs as a reference material for human cancer studies, especially in rare cases, since it is possible to increase knowledge about the characteristics of breast neoplasms in which there is a little availability of similar cases for comparative studies.

Key words: Breast cancer; Carcinosarcoma; Chromosomal rearrangements; Cytogenetic analysis; Polyploidy

\section{INTRODUCTION}

The OMS classification (1999) defines as a neoplastic type constituted by the presence of mesenchymal and epithelial components. This tumor type has infrequent occurrence in dogs; it features rapid tumor growth and prolonged periods of post-surgical survival (Misdorp et al., 1999). They are rare tumors in women and have a poor prognosis compared to other carcinomas (Tokudome et al., 2005). In the dog, the clinical and pathological characteristics are similar to those described in humans (Cassali et al., 2011).

An epidemiological study conducted in northern Italy during the period 2005-2013 compared to breast cancer incidence in bitches with records of breast tumor incidence in women from the same region and data published worldwide (Vascellari et al., 2016). It was noted that in both cases, breast tumor in bitches and women, there is a sharing of several risk factors and similarities in the incidence rate that validates the use of breast tumor in bitches as an epidemiological model for breast tumor study in humans.

Additionally, studies with molecular markers present in canine mammary tumors can be mentioned that allowed dogs as a model for human mammary neoplasias. Zuccari et al. (2012), using the techniques of immunohistochemistry and qRT-PCR, indicated caveolin-1, a cellular membrane structural protein, as a potential prognostic marker for canine mammary tumors. In 2011, using the same techniques, Zuccari et al. (2011) had already evaluated interleukin-8, chemotactic protein, as a possible prognostic marker for the same tumor type in dogs.

Regarding cytogenetics, more than 62,000 karyotypes of malignancies are listed in humans (Mitelman Database of Chromosome Aberrations and Gene Fusions in Cancer, 2013). However, in dogs, the cytogenetic study of tumors is a major challenge because the canine karyotype is the most complex among domestic mammals (Reimann-Berg et al., 2012). Among

Genetics and Molecular Research 16 (2): gmr16029433 
the chromosomal identification, difficult factors in dogs highlight the high diploid number $(2 \mathrm{n}$ $=78$ ) associated with the similarity of size and banding patterns of smaller autosomes (Breen et al., 2001).

In general, canine cancers are characterized by numerical changes, especially centric fusions (Devitt et al., 2009). As in solid human tumors, mesenchymal tumors present more than chromosomal alterations in benign or malignant epithelial neoplasms (Reimann et al., 1999). Among the different types of numerical changes, the presence of aneuploidy and centric fusions is the easiest to recognize. However, in dogs, the precise identification of chromosomal components of these changes is difficult. In the case of alterations diagnosed in dogs, the aneuploidies related to changes in sex chromosomes are the most frequently observed numerical and structural changes and rarely described, being almost exclusively found in neoplastic canine cells (Breen et al., 2001).

A cytogenetic study of 270 solid dog tumors, especially of breast tumors, showed that the second autosomal pair and X chromosome are the preferred targets of rearrangements involving numerical and structural abnormalities, respectively (Reimann et al., 1999). Additionally, chromosome pairs 1, 19, and 25 were preferentially involved in centric fusions. This study also allows the comparison between canine and human cytogenetics.

Recently, Reimann-Berg et al. (2012) have also revealed the relevance of chromosome 13 in tumor disorders in dogs. These authors claim that this chromosome is high homology with regions 4 and 8 of human chromosomes that harbor the proto-oncogene c-kit and c-MYC. Both genes are involved in the development and progression of certain human and canine tumor diseases.

Additionally, canine mammary tumors share epidemiological, clinical, biological, and genetic similar to cancer in humans (Misdorp, 2002). In this context, the comparative cytogenetics will help define genomic regions commonly affected by chromosomal abnormalities in both species and thereby facilitate the identification of important molecular changes (Reimann et al., 1999).

Considering this information, this study aimed to compare karyotype of peripheral lymphocytes and tumor cells from a dog carcinosarcoma. To assess the possible chromosomal abnormalities, numerical and structural characteristics present in neoplastic cells, conventional staining methodologies were used, C-banding and staining with base-specific fluorochromes.

Thus, in this study, the cytogenetic findings of canine mammary carcinosarcoma, rare and aggressive neoplasia compatible with those described in the literature for the same tumor type in humans, reinforced the similarity argument of breast neoplasms between these two species.

\section{MATERIAL AND METHODS}

\section{Animal}

A canine female 14-year-old Poodlethat was spontaneously occurring mammary neoplasia (Figure 1) was used in this study. The animal was attended the Veterinary Clinic Animal Health in Jequié, Bahia, in August 2012. After the clinical diagnosis, the dog received a surgical indication for breast excision as part of the treatment protocol. The animal received clinical and laboratory tests as a pre-surgical requirement.

This study was approved by the Ethics Committee on the Use of Animals of the State University of Santa Cruz, Bahia, Brazil (CEUA/BA), under protocol number 019/12.

Genetics and Molecular Research 16 (2): gmr16029433 


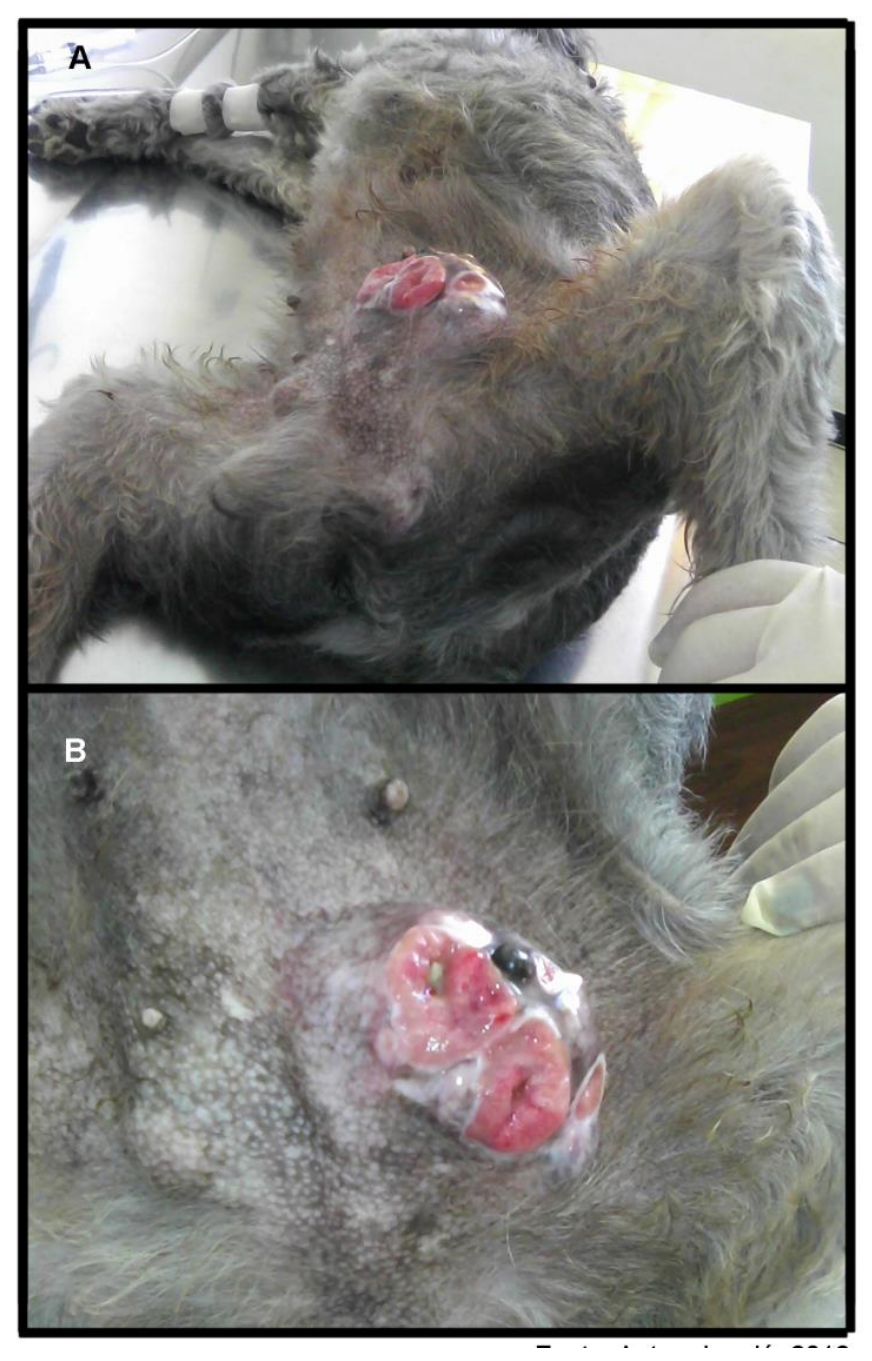

Figure 1. Poodle female dog, 14 years old, affected by the carcinosarcoma breast (A) and an enlarged tumor image (B). Jequié, 2012.

\section{Tumor collection and histopathological analysis}

For histopathological characterization, tumor tissue fragments were collected and fixed in formalin solution immediately after the surgical removal of the tumor. After the fixation, the material was included in paraffin, the tumor pieces were sliced into sections by using a microtome, mounted on blades, and stained with hematoxylin-eosin. Following this, they were examined by a light microscope. The histopathological analysis was performed in the Laboratory of Pathological Anatomy in the Hospital of Veterinary Medicine of the University Federal of Bahia. 


\section{Mitotic chromosome retrieval from blood cells and tumor cells}

Before the animal was submitted to the surgery, blood collection was performed for cytogenetic analysis. The cephalic vein was punctured with disposable syringe needle $25 \times 7 \mathrm{~mm}$ for removal of $3 \mathrm{~mL}$ of venous blood, which was placed in tubes containing the anticoagulant sodium heparin. The material was kept refrigerated for up to 1 hour, until arrival at the laboratory for cell culture. About 16 drops of collected blood were seeded in $5 \mathrm{ml}$ of culture medium for karyotype (RPMI 1640 with HEPES, fetal bovine serum and phytohemagglutinin) under aseptic conditions. The material was incubated in an oven at $38^{\circ} \mathrm{C}$ for 71 horas 30 minutes. The obtaining mitotic chromosomes from lymphocytes culture followed the protocol described by Moorhead et al. (1960).

Four pieces of the tumor (approximately $1 \times 1 \times 1 \mathrm{~cm}$ ) were collected from tumor mass and conditioned in RPMI 1640 culture medium at $4^{\circ} \mathrm{C}$. The material was kept refrigerated until arrival at cytogenetics laboratory for at most 1 hour. Cytogenetic preparations of mammary tumor fragments of cells following the methodology described by Morais et al. (2015). The slides were stained with Giemsa 5\% in phosphate buffer $\mathrm{pH} 6.8$ for chromosome count and karyotype analysis. The analysis of the material for the cytogenetic study was performed in the Cytogenetic Laboratory at Department of Biological Sciences of the State University West of Bahia at the Jequié campus.

\section{C-banding technique}

C-banding allows the selective visualization of constitutive heterochromatin, specific regions in which the chromosome presents highly repetitive DNA. This technique allows the evaluation of polymorphisms involving the just-centromeric region. The C-banding technique followed the protocol of Sumner (1972), with some modifications, such as hydrolysis in 0.2 $\mathrm{N} \mathrm{HCl}$ for $9 \mathrm{~min}$ at room temperature, treatment with barium hydroxide solution $5 \%$ at $42^{\circ} \mathrm{C}$ for $20 \mathrm{~s}$, and rapid washing with $0.2 \mathrm{~N} \mathrm{HCl}$ and incubation in citrated saline $2 \mathrm{X} \mathrm{SSC}$ at $60^{\circ} \mathrm{C}$ for $9 \mathrm{~min}$. After the procedure, the slides were washed in tap water, air dried and stained with Giemsa $10 \%$ diluted in phosphate buffer, $\mathrm{pH} 6.8$, for 8 min.

\section{Triple staining technique (CMA3/DA/DAPI)}

The chromomycin A3 fluorochrome (CMA3)/distamycin (DA)/(DAPI) technique, through the use of base-specific fluorochromes, made it possible to identify heterochromatic bands by their GC or AT content. In the DNA regions rich in TA bases, stained by the fluorochrome (DAPI ${ }^{+}$), there were few active genes, and in the GC-rich DNAs stained by the fluorochrome $\left(\mathrm{CMA}^{+}\right)$, there were many active genes. The triple staining with $\mathrm{CMA}^{+}$, DA, and DAPI was performed according to the protocol of Schmid (1980) for detecting the GC-rich regions $\left(\mathrm{CMA}^{+}\right)$or $\mathrm{AT}$ bases $\left(\mathrm{DAPI}^{+}\right)$. Distamycin acts as a competitor to avoid nonspecific markers of other fluorochromes.

\section{RESULTS}

Histological analysis of tumor fragments allowed the tumor classification as a canine breast carcinosarcoma (Misdorp et al., 1999). The total of 210 metaphases was analyzed

Genetics and Molecular Research 16 (2): gmr16029433 
between the conventional staining techniques, C-banding, and staining with base-specific fluorochromes.

The total of 105 metaphase cells from peripheral blood lymphocytes and 105 metaphases of neoplastic canine breast carcinosarcoma cells were photographed and analyzed.

The count of metaphase peripheral lymphocytes has enabled modal diploid identification number $2 \mathrm{n}=78(56.2 \%)$ (Figure $2 \mathrm{~A})$. The variation of chromosome number in lymphocytes was 41-77 chromosomes identified in 46 metaphases. However, most of these $(58.7 \%)$ had $2 \mathrm{n}$ close to the modal for the species $(70-77$ chromosomes). On the other hand, the neoplastic tissue cells showed higher chromosome number (Figure 2B and C), in a range of 104-153 chromosomes. These cells showed 80\% hypertriploid (118-136 chromosomes), 10.5\% hypertetraploid (137-153 chromosomes), 5.7\% hypotriploid (104-116 chromosomes), and $3.8 \%$ triploid $(2 \mathrm{n}=117)$.

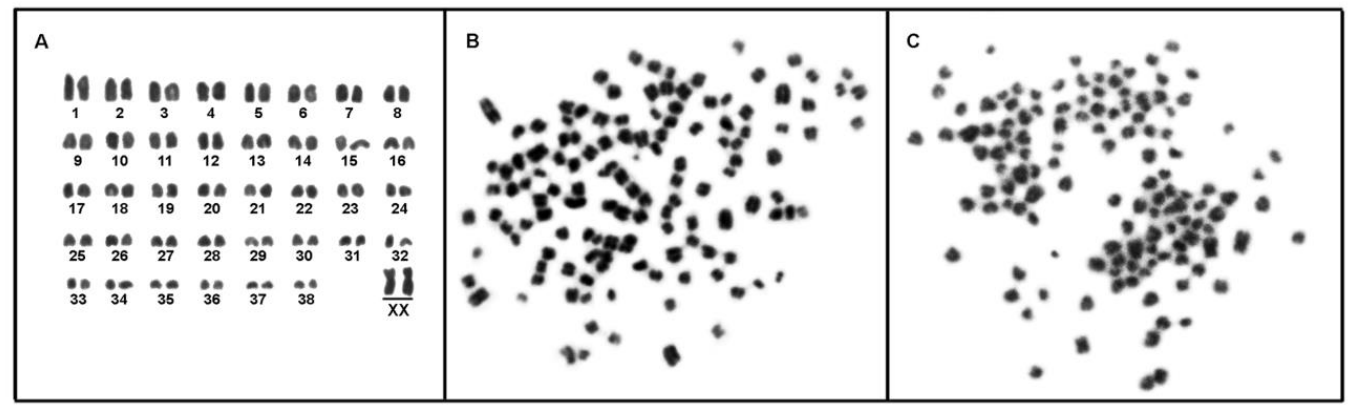

Figure 2. Karyotype of peripheral lymphocytes (A) $2 n=78$ and the breast carcinosarcoma metaphases $2 n=128$ (B) and $2 \mathrm{n}=129(\mathbf{C})$.

In addition to euploidy, aneuploid changes were also observed in these canine carcinosarcoma cells. However, it was not possible to quantify them due to the occurrence of overlaps and the small size of some chromosomes that did not permit unambiguously to characterize these structures among the identified aneuploidy, the highlighted trisomy of pair 1 and X chromosome (Figure 3). Still, metacentric and submetacentric chromosomes of different sizes were identified in tumor cells (Figure 3).

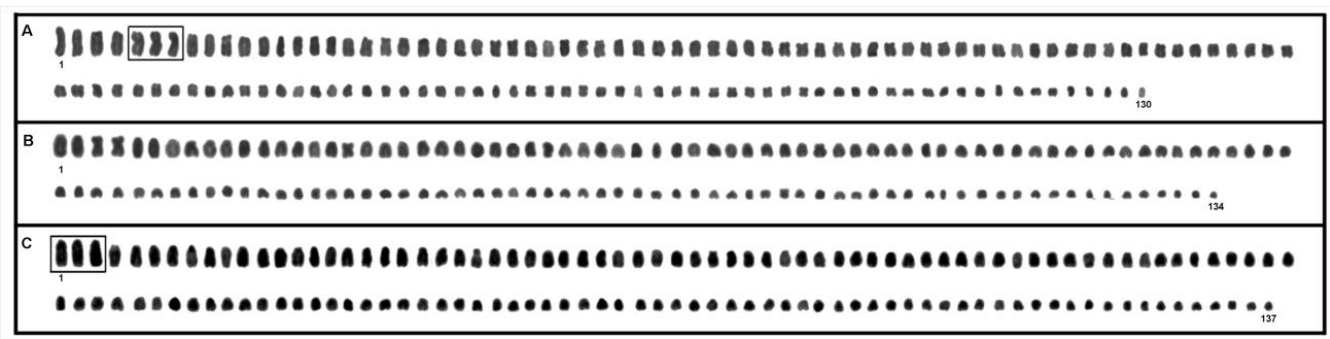

Figure 3. Cariogram metaphases of breast carcinosarcoma. A. $2 n=130 ;$ B. $2 n=134$; and C. $2 n=137$. 
In the studied samples, C-banding revealed that the chromosomes of normal cells were present in heterochromatin pericentromeric regions (Figure 4A).

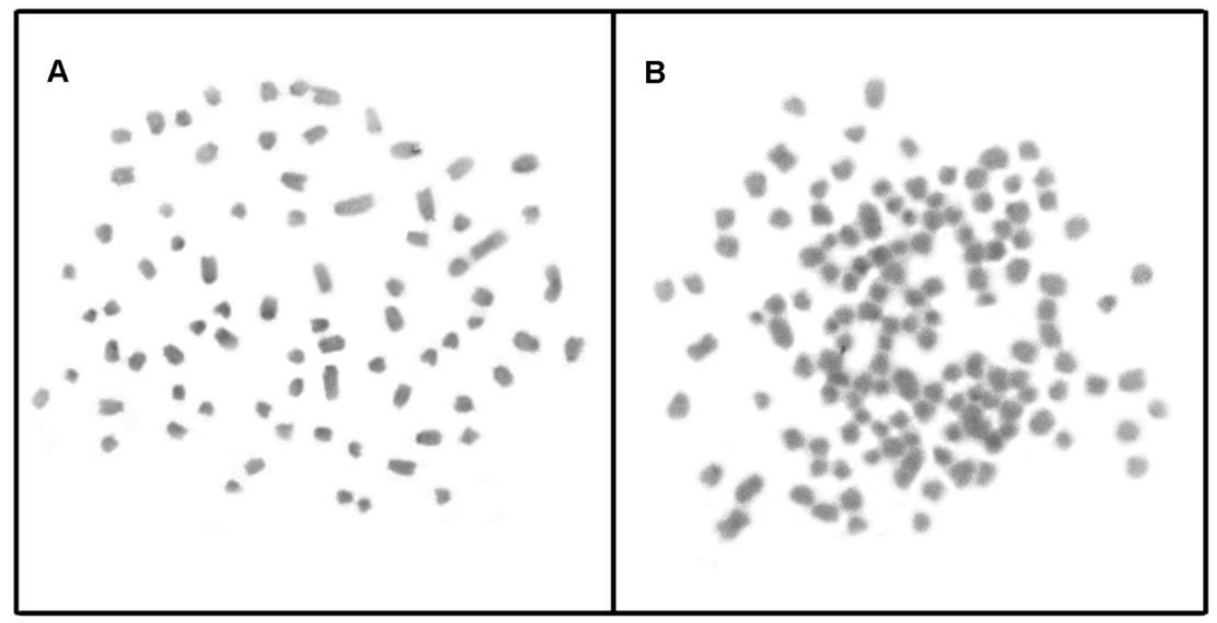

Figure 4. Lymphocyte metaphases of normal cells (A) and breast carcinosarcoma (B) after C-banding.

On the other hand, few C-band markings were found on tumor cells (Figure 4B). The results presented by staining with base-specific fluorochromes also reinforced the role of loss of heterochromatin blocks in tumor metaphase. In the case of normal cells $(2 n=78)$, segments rich in $\mathrm{GC}$ base $\left(\mathrm{CMA}^{+}\right)$were found on chromosome 10 (Figure $5 \mathrm{~A}$ ). The breast carcinosarcoma cells showed up to 11 chromosomes marked with $\mathrm{CMA}^{+}$(Figure 5B).

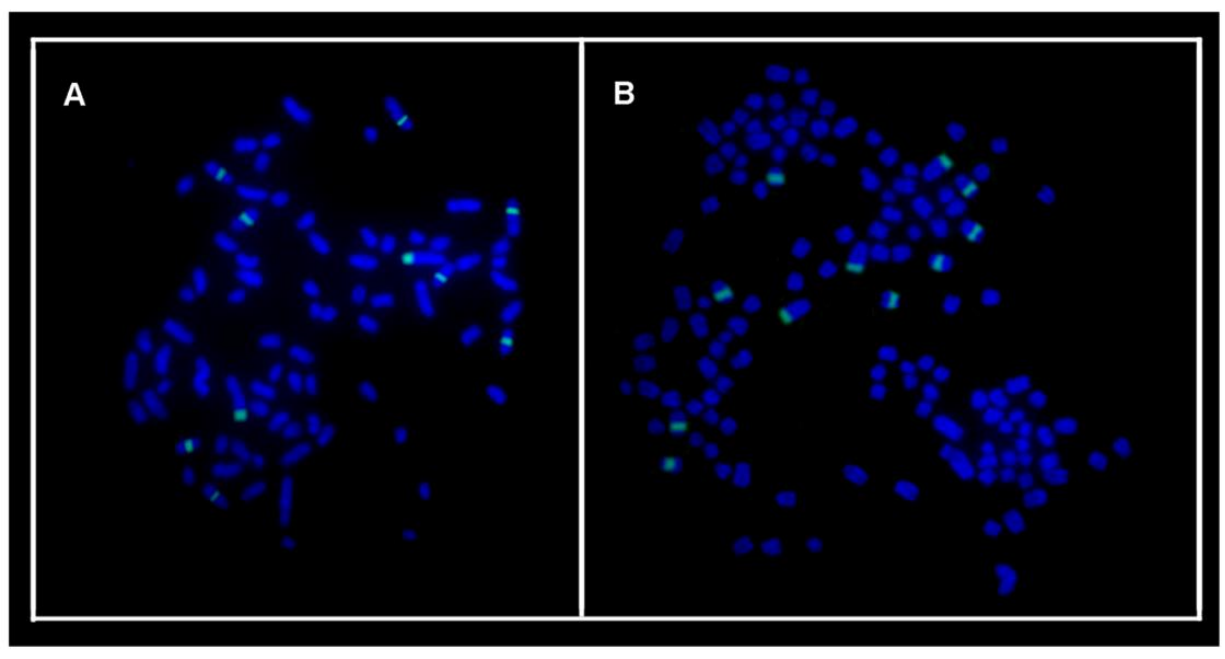

Figure 5. Lymphocyte metaphases of normal cells (A) and breast carcinosarcoma (B) after staining with basespecific fluorochromes. Green signs indicate the regions rich in $\mathrm{GC}\left(\mathrm{CMA}^{+}\right)$.

Genetics and Molecular Research 16 (2): gmr16029433 


\section{DISCUSSION}

The canine mammary carcinoma, as well as other types of canine mammary tumors, has an incidence rate and clinical and epidemiological characteristics comparable to breast tumors in women (Vascellari et al., 2016). Being unusual occurrence, case reports as the breast carcinosarcoma canine extend the cytogenetic knowledge in veterinary and human areas. In this study, we chose to evaluate a larger number of metaphases than conventionally occurs in cytogenetic studies (Morais et al., 2015); this was due to the difficulty of analysis of the canine karyotype and because it is a case report of uncommon neoplasm. Thus, the analysis of 105 metaphases from breast tumor tissue allowed us to obtain an unrestricted and reliable result. Through the metaphase counts of peripheral lymphocytes, an identification of the diploid modal number $(2 \mathrm{n}=78)$ was possible (Figure $2 \mathrm{~A})$, with the characteristic pattern coinciding for the species (Gustavsson, 1964). The observed change in chromosome number in peripheral lymphocytes showed, however, that the chromosome number of these metaphases remained close to the modal for the species. This event can be justified by the excessive spreading of chromosomes or overlap between them due to the high number of diploid in canine, featuring a technical artifact (Reimann et al., 1999; Breen et al., 2001).

High chromosome numbers of the tumor tissue cells were observed (Figure 2B and C). Chromosomal metaphase of neoplastic cells showed hypotetraploidy, hypertriploidy, hypotriploidy, and triploidy. Hypotriploide karyotypes (chromosomes 105-110) were also identified in a first-pass cell line derived from a primary, spontaneous canine carcinoma (Else et al., 1982). Stone et al. (1991) reported modal chromosome number $2 \mathrm{n}=93$ in mast cell tumors of four canines analyzed, representing $15 \%$ of the study of neoplastic cells. Additionally, numerical change on chromosomes 90-99 was observed in one of the two canine osteosarcomas studied by Mayr and Eschborn (1991).

Whereas carcinosarcomas and malignancy of breast carcinomas, osteosarcomas, and mast cell tumors in dogs, it can be inferred that the possibility of polyploidy is a byproduct of the event. If polyploidy (Figure 3) were related to the malignancy carcinosarcoma, this study could indicate the aggressive stage of the tumor examined here, since the chromosome number found was higher than those described above. However, to confirm this suggestion another experimental study with several samples of canine carcinosarcoma would be necessary.

In humans, it was identified that the breast carcinosarcoma also determines complex karyotypes with numbers near triploidy from a single stem cell, confirming the monoclonal origin of tumors (Teixeira et al., 1998). The similarities of numerical changes between carcinosarcoma in these two species also provide a new confirmation that the findings of canine cytogenetic tumors can be useful to understand the evolution of cancers in humans.

Trisomy of pair 1 and X chromosome (Figure 3) was the main identified aneuploidy since these chromosomes can be easily recognized due to the large size or differentiated morphology. Previous cytogenetic studies also indicate the occurrence of trisomy the first pair in dogs, as observed in complex tubular adenocarcinoma in the mammary gland of a female dog. In this study, $90 \%$ of the cells had $2 \mathrm{n}=79$ with trisomy of chromosome 1 (Mayr et al., 1991).

In addition to trisomy $\mathrm{X}$, the presence of more than two submetacentric chromosomes in breast carcinosarcoma cells might result from the fusion of acrocentric chromosomes in triploid cells and hypertriploids. Still, they had identified metacentric and submetacentric chromosomes of different sizes in tumor cells (Figure 3), suggesting the presence of tetraploid cells that had initially reduced chromosome number (hypertriploid metaphases) due to the

Genetics and Molecular Research 16 (2): gmr16029433 
occurrence of pericentric inversion or fusions.

This hypothesis is less parsimonious because it would involve more steps (polyploidy, mergers, and investments), but it cannot be ruled out. Furthermore, cytogenetic studies in dog mast cell cells revealed increased number of metacentric chromosomes and loss of chromosome X (Stone et al., 1991), while cases of canine osteosarcoma showed structural changes with several centric fusions (Mayr et al., 1991). Thus, high-resolution banding should be performed to confirm that changes have occurred in cancer cells beyond the numerical changes.

Using techniques of molecular cytogenetic and molecular biology to provide a more detailed analysis of cytogenetic abnormalities in canine tumors, a study with two fibrosarcomas in female Labrador identified deletion on chromosome 11 and trisomy of chromosome 30 in both cases, beyond the evidence of the involvement of the TGFBR1 gene. In that study, the cytogenetic description was possible through the unequivocal and complete assignment of all chromosomes, including translocation of chromosomes, as well as partial characterization at the molecular level (Sargan et al., 2005).

However, a much larger number of tumors must be assessed in this way to elucidate in more detail the relationship between karyotypic alterations, tumor behavior, the prognosis in dogs, and to provide a further understanding of the corresponding value of sarcomas in canines for human medicine (Sargan et al., 2005).

For example, using techniques of molecular cytogenetics, Thomas et al. (2009) tested the hypothesis of an association between breed and the distribution of the number of copies of genomic imbalances in dogs. These authors suggested that Golden Retriever and Rottweiler dogs diagnosed with appendiceal osteosarcoma with natural occurrence harbor recurrent cytogenetic changes, which are evolutionarily consistent with those reported in humans.

Unfortunately, this level of refinement of the karyotype analysis is still rarely found in cytogenetic dogs. However, while other bandings are necessary for a better understanding of the chromosomal behavior in the canine carcinosarcoma, conventional methods are also informative, as shown in this study.

The C-banding technique performed in metaphases of peripheral lymphocytes showed the presence of heterochromatin in pericentromeric regions of chromosomes, as in most species (Guerra, 1988) (Figure 4A). However, in the studied tumor cells, few C-band markings were found (Figure 4B).

In this sense, the similar use of C-banding may show more subtle chromosomal rearrangements as gains or losses in heterochromatic regions (Kasahara, 2009).

On the other hand, few C-band markings were found in tumor cells (Figure 4B), while surplus the chromosome number. Thus, the banding data indicate that $\mathrm{C}$ loss of heterochromatic segments occurred in cancer cells, which favors the occurrence of centric fusions between formally acrocentric chromosomes (Imai, 1991; Wichman et al., 1991).

The loss of heterochromatin blocks in metaphase chromosomes of the tumor was also observed by staining with base-specific fluorochromes, showing almost the same number of markings both in metaphase spreads of normal cells and neoplastic cells. Unlike what was expected, because the breast carcinosarcoma cells showed a markedly high diploid number (Figure 5B).

Together, these data demonstrate that carcinosarcoma in dogs is characterized by high genomic instability, determining karyotypes with different structural and numerical changes in the same way as in humans (Teixeira et al., 1998).

Such changes should lead to an imbalance between oncogenes and suppressor genes associated with this tumor type. This study reinforces the premise of the association between

Genetics and Molecular Research 16 (2): gmr16029433 
the findings in canine and human tumors. Consequently, the expansion of data on cytogenetics of canine cancer can bring benefits to the diagnosis and prognosis of disease for both species.

\section{Conflicts of interest}

The authors declare no conflict of interest.

\section{ACKNOWLEDGMENTS}

This study is part of the dissertation thesis of C.S.D. Morais, at the Graduate Program in Animal Science from the State University of Santa Cruz, Bahia. We thank FAPESB for granting the scholarship and veterinary Camila Calheira, owner of Animal Health Veterinary Clinic, Jequié.

\section{REFERENCES}

Breen M, Switonski M and Binns MM (2001). Cytogenetics and physical chromosome maps. In: The Genetics of the Dog (Ruvinsky A and Sampson J, eds.). Cabi, Nova York.

Cassali GD, Lavalle GE, Nardi AB, Ferreira E, et al. (2011). Consensus for the diagnosis, prognosis and treatment of canine mammary tumors. BJVP 4: 153-180.

Devitt JJ, Maranon DG, Ehrhart EJ, Bachand AM, et al. (2009). Correlations between numerical chromosomal aberrations in the tumor and peripheral blood in canine lymphoma. Cytogenet. Genome Res. 124: 12-18. https://doi. org $/ 10.1159 / 000200083$

Else RW, Norval M and Neill WA (1982). The characteristics of a canine mammary carcinoma cell line, REM 134. Br. J. Cancer 46: 675-681. https://doi.org/10.1038/bjc.1982.254

Guerra M (1988). Os Cromossomos Metafásicos e o Ciclo Mitótico. In: Introdução à Citogenética Geral (Guerra M, ed.). EditoraGuanabara Koogan, Rio de Janeiro, 1-12.

Gustavsson I (1964). The chromosomes of the dog. Hereditas 51: 187-189. https://doi.org/10.1111/j.1601-5223.1964. tb01926.x

Imai HT (1991). Mutability of constitutive heterochromatin (C-bands) during eukaryotic chromosomal evolution and their cytological meaning. Jpn. J. Genet. 66: 635-661. https://doi.org/10.1266/jig.66.635

Kasahara S (2009). Introdução à Pesquisa em Citogenética de Vertebrados. Sociedade Brasileira de Genética, Ribeirão Preto.

Mayr B, Eschborn U, Loupal G and Schleger W (1991). Characterisation of complex karyotype changes in two canine bone tumours. Res. Vet. Sci. 51: 341-343. https://doi.org/10.1016/0034-5288(91)90090-B

Misdorp W (2002). Tumors of the Mammary Gland. In: Tumors in Domestic Animals (Meuten DJ, ed.). Iowa State, University of California, 575-606.

Misdorp W, Else RW and Hellmén E (1999). Definitions and explanatory notes. In: Who historical classifications of mammary tumors of the dog and cat. (Meuten DJ, ed.). Washington, Armed Forces Institute of Pathology, 18-27.

Mitelman Database of Chromosome Aberrations and Gene Fusions in Cancer (2013). (Mitelman F, Johansson B and Mertens F, eds.). [http://cgap.nci.nih.gov/Chromosomes/Mitelman].

Moorhead PS, Nowell PC, Mellman WJ, Battips DM, et al. (1960). Chromosome preparations of leukocytes cultured from human peripheral blood. Exp. Cell Res. 20: 613-616. https://doi.org/10.1016/0014-4827(60)90138-5

Morais CS, Affonso PR, Bitencourt JA and Wenceslau AA (2015). Direct preparation protocol to obtain mitotic chromosomes from canine mammary tumors. Genet. Mol. Res. 14: 19389-19395. https://doi.org/10.4238/2015. December.29.49

Reimann N, Nolte I, Bartnitzke S and Bullerdiek J (1999). Re: Sit, DNA, sit: cancer genetics going to the dogs. J. Natl. Cancer Inst. 91: 1688-1689. https://doi.org/10.1093/jnci/91.19.1688

Reimann-Berg N, Bullerdiek J, Murua Escobar H and Nolte I (2012). Chromosome analyses in dog. Tierarztl. Prax. 3: 191-196.

Sargan DR, Milne BS, Hernandez JA, O'Brien PCM, et al. (2005). Chromosome rearrangements in canine fibrosarcomas. J. Hered. 96: 766-773. https://doi.org/10.1093/jhered/esi122

Genetics and Molecular Research 16 (2): gmr16029433 
Schmid M (1980). Chromosome banding in amphibia. IV. Differentiation of GC- and AT-rich chromosome regions in Anura. Chromosoma 77: 83-103. https://doi.org/10.1007/BF00292043

Stone DM, Jacky PB and Prieur DJ (1991). The giemsa banding pattern of canine chromosomes, using a cell synchronization technique. Genome 34: 407-412. https://doi.org/10.1139/g91-062

Sumner AT (1972). A simple technique for demonstrating centromeric heterochromatin. Exp. Cell Res. 75: 304-306. https://doi.org/10.1016/0014-4827(72)90558-7

Teixeira MR, Qvist H, Bøhler PJ, Pandis N, et al. (1998). Cytogenetic analysis shows that carcinosarcomas of the breast are of monoclonal origin. Genes Chromosomes Cancer 22: 145-151. https://doi.org/10.1002/(SICI)10982264(199806)22:2<145::AID-GCC9>3.0.CO;2-X

Thomas R, Wang HJ, Tsai PC, Langford CF, et al. (2009). Influence of genetic background on tumor karyotypes: evidence for breed-associated cytogenetic aberrations in canine appendicular osteosarcoma. Chromosome Res. 17: 365-377. https://doi.org/10.1007/s10577-009-9028-z

Tokudome N, Sakamoto G, Sakai T, Sarumaru S, et al. (2005). A case of carcinosarcoma of the breast. Breast Cancer 12: 149-153. https://doi.org/10.2325/jbcs.12.149

Vascellari M, Capello K, Carminato A, Zanardello C, et al. (2016). Incidence of mammary tumors in the canine population living in the Veneto region (Northeastern Italy): Risk factors and similarities to human breast cancer. Prev. Vet. Med. 126: 183-189. https://doi.org/10.1016/j.prevetmed.2016.02.008

Wichman HA, Payne CT, Ryder OA, Hamilton MJ, et al. (1991). Genomic distribution of heterochromatic sequences in equids: implications to rapid chromosomal evolution. J. Hered. 82: 369-377. https://doi.org/10.1093/oxfordjournals. jhered.a111106

Zuccari DA, Castro R, Gelaleti GB and Mancini UM (2011). Interleukin-8 expression associated with canine mammary tumors. Genet. Mol. Res. 10: 1522-1532. https://doi.org/10.4238/vol10-3gmr1145

Zuccari DA, Castro R, Gavioli AF, Mancini UM, et al. (2012). Immunohistochemical and molecular analysis of caveolin-1 expression in canine mammary tumors. Genet. Mol. Res. 11: 153-165. https://doi.org/10.4238/2012.January.27.2

Genetics and Molecular Research 16 (2): gmr16029433 